Max-Planck-Institut für demografische Forschung

Max Planck Institute for Demographic Research

Doberaner Strasse 114 - D-18057 Rostock · GERMANY

Tel +49 (0) 3812081 - 0; Fax +49 (0) 3812081 - 202;

http://www.demogr.mpg.de

MPIDR WORKING PAPER WP 2000-015

DECEMBER 2000

Economic Resources and Single

Motherhood:

Incidence and Resolution of Premarital

Childbearing among Young American

Women

Arnstein Aassve (aassve@ demogr.mpg.de)

This working paper has been approved for release by: Francesco C. Billari (billari@ demogr.mpg.de)

Head of the Research Group on the Demography of Early Adulthood.

(C) Copyright is held by the authors.

Working papers of the Max Planck Institute for Demographic Research receive only limited review. Views or opinions expressed in working papers are attributable to the authors and do not necessarily reflect those of the Institute. 


\title{
Economic Resources and Single Motherhood: Incidence and Resolution of Premarital Childbearing among Young American Women
}

\author{
Arnstein Aassve ${ }^{1}$
}

\begin{abstract}
This paper analyses the impact of economic resources on the likelihood of out-ofwedlock childbearing and the consequent family formation behaviour after such an event. The analysis is undertaken by specifying a multi-state, multi-spell duration model, with dynamic interactions. The results suggest that the economic resources which young women face are indeed important, not only as determinants of premarital childbearing, but also for how out-of-wedlock childbearing is resolved. Simulations indicates that welfare generosity and family resources are the most important determinants, whereas personal earnings potential plays a less important role.
\end{abstract}

\section{Introduction}

Over the last three decades family formation behaviour among young adults in the US has changed dramatically in several ways. One important dimension of this changing pattern is the sharp increase in the proportion of children living in single parent families. This is of course due to the steep rise in marital dissolution as well as the rise in out-of-wedlock childbearing. In 1998 as many as 10 percent of all children lived in single headed families in which the mother had never been married, a number that constitutes around 40 percent of all children living in single headed families (Willis 1999). Another troubling issue is that given a premarital birth, a relatively large proportion remains unmarried for relatively long periods and in many cases the mothers do not marry the biological father at all. Brien (1997) shows, however, that this varies substantially by race. Among blacks, for instance, only 26 percent of those women who experienced an out-of-wedlock birth marries the biological father within three years of the birth. Among whites, on the other hand, the equivalent figure is 78 percent, whereas the figure was around 40 percent for Hispanics.

These changes in household formation have important policy implications. There is a

\footnotetext{
1 The paper is based on my PhD thesis undertaken at Department of Economics, University of Bristol. I would like to thank Simon Burgess, Andrew Chesher, John Ermisch, Carol Propper and David Winter for very useful discussions and comments on this work. I am also indepted to Francesco Billari, Janet Currie, Montezuma Dumangane, Jan Hoem, Jennifer Ireland, Hans-Peter Kohler, Tony Lancaster, Paris Nearchou and Kees Jan van Garderen, who all provided valuable comments and suggestions. The responsibility of any remaining errors lies with the author.
} 
serious concern over the retreat from the traditional pattern of family formation. In particular, single parent families are associated with a higher incidence of poverty and welfare dependency. Growing up in a single parent family, therefore, generally lowers the welfare of the child, both in terms of educational achievement and other important child outcomes.

Several authors have investigated how economic variables are related to pre-marital childbearing. In this paper the family formation process is extended beyond the event of out-of-wedlock childbearing. It provides therefore a more complete picture of the process of out-of-wedlock childbearing and its relation to economic resources. The questions we aim to answer are: How do economic incentives affect the likelihood of premarital childbearing? What is the role of economic resources on family formation decisions taking place after premarital childbearing? What is the relative importance of the different economic resources on the family formation process? We distinguish three sources of economic support and economic opportunities, which are likely to influence these decisions: 1) Family resources, 2) own personal resources, and 3) state welfare support.

These issues are investigated by specifying a dynamic econometric model with multiple destinations and multiple spells. This recognises the fact that marriage and fertility transitions are highly inter-related dimensions of a joint family formation process. The econometric model is similar to the mixed multivariate proportional hazard models as outlined by van den Berg (2000).

The empirical model is highly non-linear and includes dynamic interactions, a feature that makes the parameter estimates hard to interpret alone. Moreover, they are not necessarily very informative for the purpose of policy analysis. We therefore undertake a detailed simulation analysis as a means of performing sensitivity analysis of the parameter estimates with respect to some crucial statistics on out-of-wedlock childbearing behaviour.

The paper is outlined as follows. Section 2 provides an overview of the literature and discusses theoretical issues. Section 3 presents the empirical model and the data. Section 4 discusses the covariates. Section 5 presents the results, section 6 presents the simulations, whereas section 7 concludes the paper.

\section{Background and previous research}

In general economic theory defines the relationship between economic resources and family formation behaviour as being rather complex. This is particularly the case for out-ofwedlock childbearing since this is not only a particular aspect of fertility behaviour - it is also a crucial part of the marriage formation process. Thus theories aiming at explaining the role of economic resources in out-of-wedlock childbearing have to take both of these aspect into account (Willis 1999). This section provides an economic perspective of the role played by one's own personal resources, state welfare support, and family resources in explaining family formation behaviour. The section ends with a review of the empirical literature.

In the simple economic setting, marital fertility is explained in terms of opportunity costs of children together with the notion of child quality (Becker 1965; Becker \& Lewis 1973). Assuming that child quality is exogenous, the basic economic framework predicts 
that increased levels of personal resources, normally measured in terms of labour earnings, reduces the demand for children ${ }^{2}$. In terms of search models of marriage formation, high personal earnings is predicted to increase the person's marriage prospects, and therefore reduce the risk of having children outside of marriage. This can be thought of as a good catch effect and reflects that marriage offer rates are higher among high earning women, increasing the probability of marriage. At the same time, however, women might become more selective if they realise that they are attractive in the marriage market, which of course reduces the probability of marriage.

High personal earnings is likely to reduce the importance of parental support, as well as the income normally received from a spouse within marriage. This resembles a self-reliance effect associated with high levels of personal resources (Aassve et al (2000)), which predicts not only that young women are more likely to leave the parental home as their income increases, but also that marriage becomes less important as an institution to start their own family. The latter highlights the important role of the spouse's earnings potential in the marriage formation process. Willis (1999) shows that under certain conditions, women might consider out-of-wedlock childbearing to be more beneficial compared to childbearing within marriage. In particular Willis shows that this might be the case when, first of all, women have an income which is high enough that they are willing to rear children with their own resources only, second, the quality of single men is poor, and third, there is excess supply of women in the marriage market. Willis argues that under such circumstances the gains resulting from coordinating resources within marriage is not large enough to induce marriage, and hence, marital childbearing.

An issue that has received considerable attention recently is the alleged effect of generous welfare schemes on out-of-wedlock childbearing among young women. The policy implication, it is often claimed, is that welfare benefits, normally biased in favour of single headed families with low income and dependent children only, tend to induce out-ofwedlock childbearing (eg. Becker 1991; Rosenzweig 1999). Thus, entering parenthood at an early age, and possible before marriage, might be considered more attractive among women for which the future economic prospects are limited due to social exclusion and discrimination. It is common to use the variation in generosity levels across states in order to identify the effect on pre-marital childbearing. The central problem of this approach is that the level of welfare benefits might be set endogenously by the authorities. State differentials in terms of welfare generosity are, at least to some extent, likely to serve as an indicator of fundamental differences in state attitudes towards out-of-wedlock childbearing. Thus a positive relationship between welfare generosity and out-of-wedlock childbearing might reflect the authorities' response to high rates of premarital childbearing, rather than young women responding to the levels of generosity.

Parents are likely to be an important source of financial support in the early years of adulthood, as it is not uncommon for parents to provide financial support for the offspring's educational career as well as helping out in the costly venture of setting up their own house-

\footnotetext{
2 This result is based on the assumption that child rearing is undertaken by the parents. Ermisch (1989) shows that this simple theoretical prediction may be different when the household has the opportunity to purchase child care externally. Also see Ermisch and Cigno (1989) for an economic analysis of the timing and tempo of fertility decisions.
} 
hold. These transfers will, of course, influence the offspring's family formation behaviour.

In general we would expect the level of family income to be negatively associated with out-of-wedlock childbearing. There are several reasons for this. In terms of young adults leaving the parental home, which is linked both to marriage and fertility timing, we expect high levels of parental resources to increase the utility associated with living in the parental home. Thus, high levels of parental resources makes one's own family formation less attractive, all else being equal. Search and matching models of marriage, on the other hand, predicts that high parental resources signal, at least in part, the quality of the young individual as a marriage partner. Thus, a high level of parental resources will increase the marriage offer rate, which in turn will make marriage more likely. A consequence of this positive effect on marriage formation is that higher parental income will make premarital childbearing less likely. In summary, therefore, we would expect the negative effect from high family income levels to be stronger for pre-marital childbearing, than for marriage.

The relationship between parental resources and the offspring's family formation timing can also be viewed in terms of intergenerational effects derived from preferences and norms. Parents' educational attainment and working career, which to a large extent determines family income, are highly correlated with the offspring's educational choice and career pattern. This is therefore an equally plausible explanation for the negative relationship between family income and timing of the family formation process. Thus the effect of family resources on family formation requires a broader interpretation than just the financial incentives associated with intergenerational transfers.

The majority of the empirical work on the issue of premarital childbearing has taken a sociological viewpoint towards explanation, thus emphasising the importance of family background and intergenerational effects. Cooksey (1987) for instance, find a strong negative association between out-of-wedlock childbearing and parents education. She also finds that young women growing up in single headed families have a higher risk of experiencing out-of-wedlock childbearing. Antel (1992) supports this view, as he finds premarital childbearing to be positively associated with mothers' welfare dependency. Yamaguchi and Kandel (1987) finds that early cohabitation and poor performance at school, as well as use of illicit drugs and dropping out of school are positively associated with premarital pregnancies. Other studies have suggested that stressful events, such as rapid changes in family structure as well as frequent changes in household location at young age, are positively associated with out-of-wedlock childbearing (Antel 1988; Abrahamse et al 1988). Yet others have emphasised the role of imperfect information among young adults in terms of opportunities in the labour market, as well as lack of understanding of the negative consequences normally associated with premarital childbearing (see Hanson et al 1988 as well as Antel (1988) for evidence of this hypothesis). Another strand of this literature has emphasised the role of marriage markets in explaining out-of-wedlock childbearing. This hypothesis suggest that women living in areas with poor marriage markets, normally measured by the number of available mates, are more likely to bear children outside marriage. South (1996) finds that white women are less likely to marry, and hence more likely to bear children out of wedlock, in areas where men face relatively unstable employment opportunities and poor earnings prospects. South and Lloyd (1992) find a significant relationship between the ratio of males to females and the likelihood of experiencing premarital childbearing. 
There are relatively few papers taking an economic viewpoint. The most detailed work to date on the relationship between premarital childbearing and welfare generosity is undertaken by Rosenzweig (1999). Using data from the NLSY, and making control for state and cohort fixed effects, he finds a strong relationship between AFDC levels and premarital childbearing among those aged 19-22, whereas those aged 14-18 were insensitive to the level of welfare available to them. The results are supported by Hoffman and Foster (2000) who replicated the work by Rosenzweig (1999) with data from the PSID.

Duncan \& Hoffman (1990) investigated the effect of welfare generosity, measured in terms of AFDC levels, and economic opportunities on the incidence of premarital childbearing among black teenagers using data from the PSID. Using logistic regression they found the effect of welfare generosity to only have a weak, and insignificant, effect on premarital childbearing. In contrast, they found a negative relationship between family income and out-of-wedlock childbearing. An et al (1993), also using the PSID, found that the mother's education, which is positively associated with the offspring's educational level and future earnings, was negatively associated with pre-marital childbearing, though they found no strong link with the welfare generosity level.

Implementing a nested logit model which includes premarital pregnancy, pregnancy resolution, and the occurrence of marriage before childbirth in three different stages, Lundberg and Plotnick (1995) find a relatively strong association between welfare generosity and the incidence of premarital childbearing for white women, but no strong effect among black women.

\section{Data and empirical specification}

\subsection{Model specification}

The family formation process is here modelled as a duration model with multiple destinations and multiple spells. This econometric specification is similar to the mixed multivariate proportional hazard as outlined by van den Berg (2000), and recognises the fact that marriage and fertility transitions are inter-related dimensions of a joint family formation process. Figure 1 illustrates the structure of the econometric model.

All women start the family formation process as being single without children. They can then either marry or have a child and become a single mother. The single mother will either marry, or have another child outside of marriage. Alternatively she might stay on as a single mother until the censoring date. Table 1 lists all the possible family status categories included in the econometric model. Family status 5 and 6 represent second births and are treated here as absorbing states. Thus if the woman does not reach second birth within the end of the survey she becomes censored. It is clear from figure 1 that the empirical model also incorporates marital fertility and marital dissolution but these transitions are not analysed here.

The movements between the family states are restricted according to table 2 , and has the following implications. First, child mortality is ignored which implies that nobody in this 


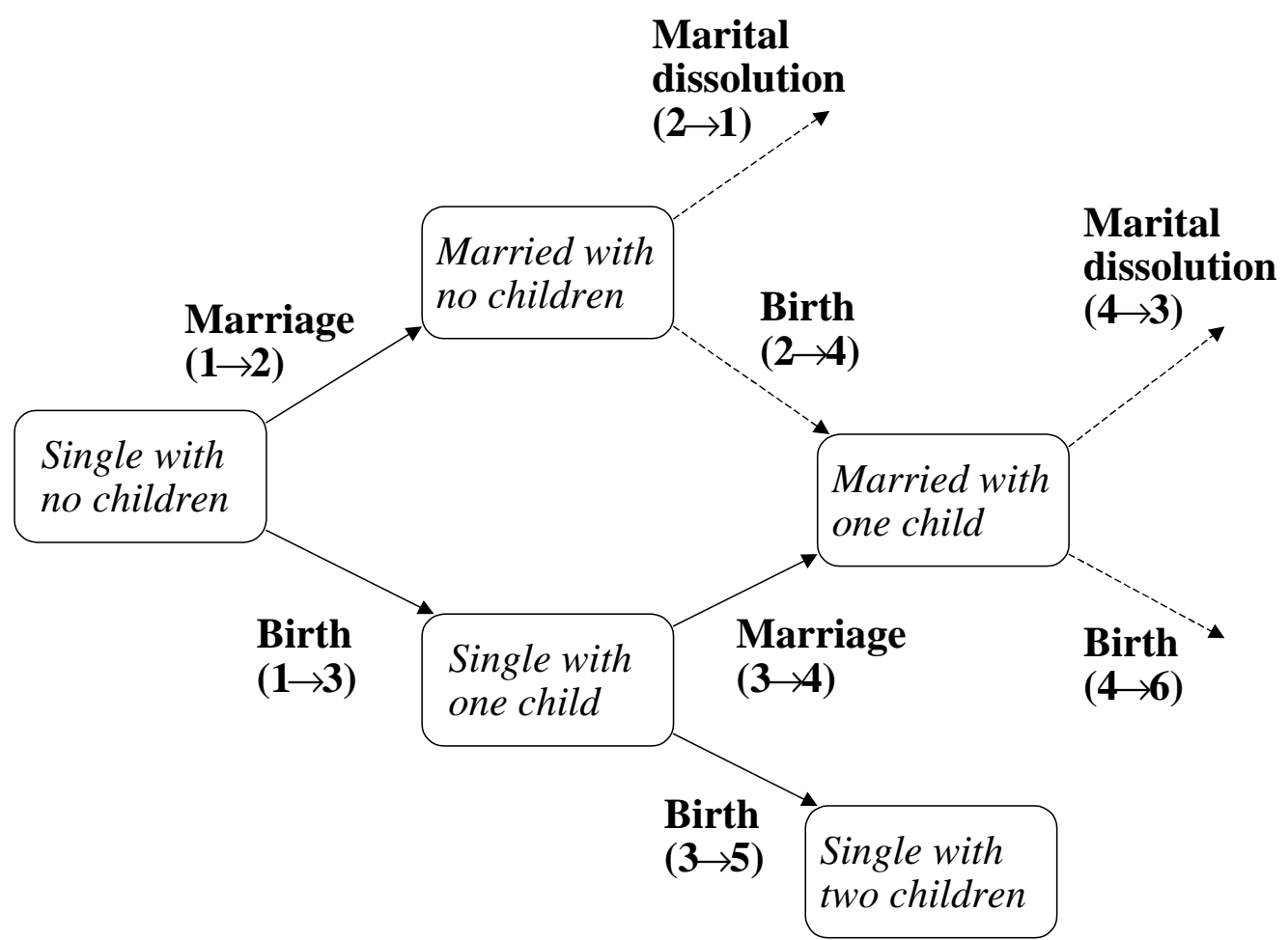

Figure 1: Structure of empirical model. Family status are denoted by the rounded square boxes, wheras the arrows denotes the family formation transitions. Transitions denoted by the dotted arrows are also estimated as part of the econometric model, but not analysed here.

Table 1: Listing of family statuses:

\begin{tabular}{|ll|}
\hline Family status 1: & "Not Married, No Children" \\
Family status 2: & "Married, No Children" \\
Family status 3: & "Not Married, One Child" \\
Family status 4: & "Married, One Child" \\
Family status 5: & "Not Married, Two Children" \\
Family status 6: & "Married, Two Children" \\
\hline
\end{tabular}


Table 2: Listing of all possible family formation transitions.

\begin{tabular}{|c|c|c|}
\hline $\begin{array}{l}\text { Marriage transitions: } \\
\text { "Not Married \& No Children" (1) } \\
\text { "Not Married \& No Children" (1) } \\
\text { "Not Married \& One Child" (3) }\end{array}$ & $\begin{array}{l}\rightarrow \\
\rightarrow\end{array}$ & $\begin{array}{l}\text { "Married \& No Children" ( } 2 \mathrm{f}) \\
\text { "Married \& No Children" ( } 2 \mathrm{~s}) \\
\text { "Married \& One Child" (4) }\end{array}$ \\
\hline $\begin{array}{l}\text { Fertility transitions: } \\
\text { "Not Married \& No Children" (1) } \\
\text { "Married \& No Children" (2) } \\
\text { "Not Married \& One Child" (3) } \\
\text { "Married \& One Child" (4) }\end{array}$ & $\begin{array}{l}\rightarrow \\
\rightarrow \\
\rightarrow\end{array}$ & $\begin{array}{l}\text { "Not Married \& One Child" ( } 3) \\
\text { "Married \& One Child" (4) } \\
\text { "Not Married \& Two Children" ( 5) } \\
\text { "Married \& Two Children" (6) }\end{array}$ \\
\hline $\begin{array}{l}\text { Marital dissolution transitions: } \\
\text { "Married \& No Children" (2) } \\
\text { "Married \& One Child" (4) }\end{array}$ & $\begin{array}{l}\rightarrow \\
\rightarrow\end{array}$ & $\begin{array}{l}\text { "Not Married \& No Children" (1) } \\
\text { "Not Married \& One Child" (3) }\end{array}$ \\
\hline
\end{tabular}

sample undertakes a transition $4 \rightarrow 2$ or a transition $3 \rightarrow 1$. Second, women giving birth to twins are excluded, which rules out transitions $2 \rightarrow 6$ and $1 \rightarrow 5$. And finally, both marriages and fertility events are recorded by exact dates, which means that a marriage will never take place at the same time as a fertility event ${ }^{3}$, excluding transitions $1 \rightarrow 4$ and $4 \rightarrow 5$.

Table 2 summarises the family formation transitions that take place within the specified framework. Marriage can occur through two different routes. Marriage before childbearing is denoted as a transition $1 \rightarrow 2$, whereas marriage after childbearing is denoted as $3 \rightarrow 4$. All subsequent marriages (denoted $1 \rightarrow 2(\mathrm{~s})$ ), are treated as one process and are separate from first marriages. Fertility events take place through four different routes. The first is a premarital birth and is denoted as a transition $1 \rightarrow 3$. The second is first childbirth within marriage (transition $2 \rightarrow 4$ ). The third is to have a second birth outside marriage, (denoted as $3 \rightarrow 5$ ), and the fourth is to have a second birth within marriage, and is denoted $4 \rightarrow 6$. In this framework we analyse the family formation process up until the second birth, which implies that state 5 and state 6 are absorbing.

The econometric model, for which the details are given in Appendix A, is a competing risk specification with multiple spells ${ }^{4}$. In this framework the probability of transiting from a family status $i$ to family status $k$ is given by:

$$
h_{i k}^{r}\left(t \mid x(t), v^{r}\right) \exp \left(-\sum_{j=1}^{k} I_{i j}^{r}\left(t \mid x(t), v^{r}\right)\right) d t .
$$

where $h_{i k}^{r}$ denotes the hazard function for a transition from $i$ to $k$ in the $r^{\prime}$ th spell, $\mathrm{x}(t)$ denotes the vector of covariates, some of which are time-varying, $v^{r}$ is a random variable capturing unobserved heterogeneity in spell $r$, and $I_{i j}^{r}$ denotes the integrated hazard.

It is not possible to observe all individual specific characteristics that determines behaviour, but it is necessary to control for these unobserved characteristics in order to avoid

\footnotetext{
3 If, on the other hand, events were recorded in discrete time, the likelihood of observing marriage at the same time as child birth would be relevant. This would in general complicate the modelling scheme considerably.

4 The model is implemented and estimated using the SAS matrix language (IML). Estimation of the most elaborate model is relatively computer intensive, and it takes about 5 to 6 hours to perform one single iteration using a Sun Spark-station. The computer programs are available from the author on request, although no support can be given.
} 
biased parameter estimates (see Lancaster (1990) for details). Here unobserved heterogeneity is captured by the random variable $V$, which entails introduction of a constant "covariate" in $x(t)$. It is specified as a univariate discrete distribution with two points of support $v$ (i.e. masspoints), and with associated probability masses $p$ and the expected value of $V$ is required to be zero implying:

$$
\sum_{m=1}^{2} v_{m} p_{m}=0
$$

in addition to the restriction $\sum_{m=1}^{2} p_{m}=1$. This is similar to the non-parametric masspoint specification employed by Heckman and Singer (1984) although here there is no search for a likelihood maximising the number of mass points ${ }^{5}$. An advantage of using this nonparametric approach is that it avoids making restrictive assumptions about the distribution function of $v$. A drawback, however, is that the interpretation of $v$ becomes difficult. Since $v$ is estimated non-parametrically, it will capture any unobserved heterogeneity which may arise from a range of different sources. It is difficult, therefore, to make any statements other than that positive values of $v$ reflects "mover" behaviour and negative values reflects "stayer" behaviour. Section 5 provides a tentative interpretation of the masspoints regarding marriage after out-of-wedlock childbearing.

\subsection{The NLSY sample}

We use a sample of $3715^{6}$ women from the National Longitudinal Survey of youth (NLSY). The data is taken from 1979 to 1992 and the age distribution is in the range 14 to 20 years when first interviewed in 1979. The data reveal quite different patterns of the family formation process with respect to the different race groups. Black women marry later than both Hispanic and white women and Hispanic women marry at an earlier age than whites. Black women have first premarital birth at a younger age than the other race groups. For second premarital birth there is no great difference between Hispanic and black women. Child bearing within marriage takes place on average three years later than child bearing outside of marriage, and the birth of a second child within marriage takes place 1.7 years after the first birth.

Every woman in the sample is recorded with a "transition history" defined over the family states listed in table 1 and the durations between the family formation events. Table 4 shows the frequency distribution of these sample transition types. For instance the transition

\footnotetext{
5 The current specification implies that the masspoints are independent across spells, which invokes the assumption that unobserved heterogeneity is uncorrelated across spells. This is in contrast to Aassve et al (2000) where unobserved heterogeneity, again modelled by the use of non-parametric masspoints, is allowed to be correlated across spells. However, including past duration variables explanatory covariates, as is done here, precludes this possibility. This is simply because the correlated unobserved heterogeneity terms will themselves be correlated with past durations and occurences, and consequently produce biased parameter estimates. Also note that the current specification does not allow for correlation across destination states since we assume independence of the competing risks. This is in contrast to Lillard et al (1999), who identify correlation in unobserved behaviour between the hazard of marriage and the hazard of conception.

6 The original sample includes 6283 women. The reduction in sample size is mainly caused by missing values in the covariates, as well as incomplete family histories. The number of missing values were reduced by implementing data cleaning procedures as suggested in Cole \& Currie (1994).
} 
Table 3: Mean age for transitions

\begin{tabular}{lcccc}
\hline Age at: & All & Whites & Hispanics & Blacks \\
\hline first transition & 22.68 & 22.98 & 22.23 & 22.29 \\
\hline first marriage (prior to birth) & 21.85 & 21.93 & 21.29 & 22.15 \\
first marriage (after 1st birth) & 22.29 & 22.08 & 21.49 & 22.89 \\
\hline first premarital birth & 20.11 & 20.22 & 20.33 & 19.99 \\
second premarital birth & 22.96 & 23.71 & 22.68 & 22.75 \\
\hline first birth (married) & 23.22 & 23.48 & 22.43 & 23.03 \\
second birth (married) & 24.92 & 25.05 & 24.64 & 24.76 \\
\hline
\end{tabular}


Table 4: Frequency table of family transition histories, sample versus simulated (in brackets). 1 = "Not married, no children, 2 = "Married, no children", 3 = "Not married, one child", 4 = "Married, one child", 5 = "Not married, two children, 6 = "Married, two children".

\begin{tabular}{lccccccc}
\hline & All & \multicolumn{2}{c}{ Whites } & \multicolumn{2}{c}{ Hispanics } & \multicolumn{2}{c}{ Blacks } \\
\hline Transition type & Sample & Sample & Simul. & Sample & Simul. & Sample & Simul. \\
\hline 1 & 13.8 & 13.7 & $(11.6)$ & 12.3 & $(10.4)$ & 15.0 & $(12.3)$ \\
$1 \cdot 2$ & 10.8 & 13.6 & $(13.0)$ & 7.7 & $(8.8)$ & 6.6 & $(4.7)$ \\
$1 \cdot 3$ & 5.2 & 2.2 & $(1.1)$ & 5.8 & $(2.2)$ & 11.4 & $(7.4)$ \\
$1 \cdot 2 \cdot 1$ & 2.1 & 2.4 & $(3.5)$ & 1.6 & $(2.1)$ & 1.7 & $(1.6)$ \\
$1 \cdot 2 \cdot 4$ & 10.1 & 12.8 & $(12.8)$ & 8.6 & $(10.9)$ & 5.0 & $(5.4)$ \\
\hline $1 \cdot 3 \cdot 4$ & 1.6 & 1.4 & $(1.3)$ & 1.0 & $(1.5)$ & 2.3 & $(2.7)$ \\
$1 \cdot 3 \cdot 5$ & 11.8 & 3.6 & $(4.2)$ & 9.6 & $(12.3)$ & 31.1 & $(33.1)$ \\
$1 \cdot 2 \cdot 1 \cdot 2$ & 1.4 & 2.1 & $(1.6)$ & 0.8 & $(1.0)$ & 0.3 & $(0.3)$ \\
$1 \cdot 2 \cdot 1 \cdot 3$ & 0.3 & 0.5 & $(0.2)$ & 0.2 & $(0.2)$ & 0.0 & $(0.3)$ \\
$1 \cdot 2 \cdot 4 \cdot 3$ & 1.6 & 1.5 & $(1.2)$ & 2.1 & $(0.7)$ & 1.2 & $(0.9)$ \\
\hline $1 \cdot 2 \cdot 4 \cdot 6$ & 27.9 & 33.2 & $(34.8)$ & 36.1 & $(32.3)$ & 11.0 & $(13.0)$ \\
$1 \cdot 3 \cdot 4 \cdot 3$ & 0.2 & 0.2 & $(1.3)$ & 0.3 & $(1.8)$ & 0.2 & $(3.4)$ \\
$1 \cdot 3 \cdot 4 \cdot 6$ & 6.8 & 4.7 & $(3.0)$ & 7.7 & $(4.7)$ & 10.8 & $(4.5)$ \\
$1 \cdot 2 \cdot 1 \cdot 2 \cdot 1$ & 0.2 & 0.2 & $(0.1)$ & 0.2 & $(0.0)$ & 0.1 & $(0.1)$ \\
$1 \cdot 2 \cdot 1 \cdot 2 \cdot 4$ & 0.9 & 1.3 & $(1.3)$ & 0.6 & $(0.7)$ & 0.2 & $(0.2)$ \\
\hline Other & 5.5 & 6.5 & $(6.8)$ & 5.7 & $(8.7)$ & 2.9 & $(8.1)$ \\
\hline
\end{tabular}

sequence "married - first child - second child" will produce transition history $1 \cdot 2 \cdot 4 \cdot 6$. Table 4 shows that this is in fact the most common form of family formation and as many as 27.9 percent of the sample belong to this group. 13.8 percent of the sample do not make any transitions. A large proportion of the sample are right censored as only 50.8 percent of the sample reach the absorbing states (state 5 or state 6 ). 10.8 percent of the sample get married but have no children (history type 1.2) and 10.1 percent of the sample are censored when they are married and have one child $(1 \cdot 2 \cdot 4)$. 5.2 percent are censored as unmarried with one child (1.3) and 11.8 percent are censored as unmarried with two children $(1 \cdot 3 \cdot 5)$

The transition type frequencies vary substantially between the three race groups. 11.4 percent of blacks have transition history 1.3 whereas only 2.2 percent of whites belong to this group. The percentages show that black women are less likely to marry before first child birth. The most dramatic differences are for transition types 1·3.5 and 1·2 4 6. 31.1 percent of blacks are having both first and second childbirth out-of-wedlock, whereas only 3.6 percent of white women follow this route. Only 11 percent of black women undertake the most common route of $1 \cdot 2 \cdot 4 \cdot 6$ compared to 33.2 and 36.1 percent for whites and Hispanics respectively.

\section{Empirical issues}

\subsection{Personal earnings capacity}

We use the predicted wage rate as an exogenous measure of the young women's earnings capacity (see Mincer (1974) for details). Data from the Current Population Survey (CPS) 
Table 5: Probit equation for labour force participation and Ordinary Least Squares estimates of $\log$ wages

\begin{tabular}{|c|c|c|}
\hline \multicolumn{3}{|c|}{ Probit labour force participation equation } \\
\hline Covariate & Coefficient & Std. error \\
\hline Age & 0.070 & $(0.001)$ \\
\hline Age squared & -0.0011 & $(0.00001)$ \\
\hline Years of education & 0.092 & $(0.001)$ \\
\hline African American & -0.029 & $(0.012)$ \\
\hline Living in urban area & 0.067 & $(0.008)$ \\
\hline Currently enrolled & -2.923 & $(0.053)$ \\
\hline \multicolumn{3}{|c|}{+ State and year dummies $(\mathrm{N}=184349)$} \\
\hline \multicolumn{3}{|c|}{ OLS regression of log wage } \\
\hline Covariate & Coefficient & Std. error \\
\hline Mills ratio & 0.775 & $(0.042)$ \\
\hline Age & 0.091 & $(0.002)$ \\
\hline Age squared & -0.0012 & $(0.00003)$ \\
\hline Years of education & 0.114 & $(0.002)$ \\
\hline African American & -0.042 & $(0.005)$ \\
\hline Living in urban area & 0.148 & $(0.004)$ \\
\hline \multicolumn{3}{|c|}{ + State and year dummies $\left(\mathrm{N}=79224, \mathrm{R}^{2}=0.23\right)$} \\
\hline
\end{tabular}

is used to estimate the wage equation from which the predicted wages are derived. The motivation for using a large external data-set for this purpose is twofold. First, the NLSY sample is relatively modest (3715 women), which implies that we might encounter groups with relatively small number of observations, in which the predicted wages might be biased. The other problem associated with using the sample to predict wages is the possible bias generated by the early exit of respondents into the absorbing states (second childbirth). The observed wage rates of the remaining sample (those who make transitions later), therefore, may not be representative for their age-group. Using data from the CPS, which contains around 60000 respondents overcomes both of these problems.

We apply a two step procedure in order to control for self-selection into the labour force, where women are defined as participating in the labour force if they report the usual hours worked in a week to be positive. The first step consist of a Probit model of labour force participation, from which the Inverse Mills Ratio (IMR) is computed. This is then included as a covariate in the second step which is an Ordinary Least Squares (OLS) estimator on $\log$ wages.

Table 5 shows the results. They conform well to the existing literature. Women with higher education or who live in urban areas tend to have higher participation rates. Black women have slightly lower participation rates. Being currently enrolled in a school or university has a strong negative impact on participation. The OLS regression shows that wages are positively associated with age but at a declining rate. Living in an urban area is associated with higher wages, whereas the coefficient on education is within the standard range reported in the literature. Black women earn less than Hispanics and whites.

These estimates are used to construct the predicted wage levels ${ }^{7}$, which consequently

7 The fact that women are assumed to start their family formation process at the age of 13 , and wages are only estimated from the year starting from 1978, implies that out of sample predictions have been undertaken. 
Table 6: Ordinary Least Square estimation of family income on parental and background characteristics.

\begin{tabular}{lcc}
\hline OLS regression of family income & & \\
\hline Variable & Coefficient & Standard Error \\
\hline Age of mother & 0.021 & $(0.014)$ \\
Age of mother squared & -0.0002 & $(0.00016)$ \\
Mother completed high school & 0.233 & $(0.035)$ \\
Mother has college degree & 0.302 & $(0.048)$ \\
Mother works part time & 0.070 & $(0.037)$ \\
Mother works full time & 0.158 & $(0.032)$ \\
Mother had first child as a teenager & -0.077 & $(0.035)$ \\
Father completed high school & 0.161 & $(0.035)$ \\
Father has college degree & 0.285 & $(0.044)$ \\
Father works part time & 0.298 & $(0.054)$ \\
Father works full time & 0.551 & $(0.035)$ \\
Parents live in a rural area & -0.078 & $(0.041)$ \\
+ state dummies & & \\
\hline N $=3256$ & & \\
R-squared $=0.231$ & & \\
\hline
\end{tabular}

are mapped into the NLSY sample using the background characteristics listed in table 5. The predicted wage levels are essentially the average wage levels of the group of women to which the women in the NLSY sample belong to. It is therefore the wage rate the woman is most likely to expect and is interpreted as a measure of the woman's expectation regarding her future earnings potential.

\subsection{Parental resources and family income}

Parental resources are measured by two alternative specifications of family income. In the first we use the actual family income as it is reported in $1979^{8}$ by the NLSY. This is the total family income minus the income of the respondent. A significant drawback, however, is that it is not available prior to 1979. Since some women left the parental home prior to 1979 , the actual family income will refer to the partner's income, and not the parent's income. The second specification is meant to overcome this problem. Instead of using the actual family income in 1979 we construct the predicted family income, based on those women who still live in the parental home in 1979. The predicted family income is then mapped onto those women who had left the parental home. Table 6 shows the results of the OLS regression used to generate the predicted family income variable.

The results conform to our expectations. Age is positively associated with family income, but at a declining rate. The parents educational level is also positively associated with family income and there is little difference between mother and fathers' educational attainment. In terms of parents' work status the results indicates quite clearly that the work status of the father dominates. The results also show a negative relationship between family income and the timing of the parent's family formation process, which is measured by whether the mother gave first birth as a teenager. However, the magnitude is not large and

8 The parental income reported in 1979 refers to the income in previous calendar year, i.e. 1978. 
the coefficient is not statistically significant at the five percent level. Finally we see there is a positive association between income and living in an urban area.

\subsection{Women' educational attainment and other background variables}

Due to the endogeneity of women's education we have not included this as a covariate in our specifications. The endogeneity problem is essentially that women who marry or have a child early in their life may terminate their education in response to these events. Thus the associated parameter is likely to be biased, and might affect other covariates that are correlated with educational attainment, such as her earnings. As an alternative we use the woman's AFQT score, which is positively correlated with years spent in education, but have a higher degree of exogeneity with respect to her family formation choices. Given the positive correlation to the time spent in education, we expect high levels of AFQT to have a delaying effect on marriage, and we might expect it to have a negative effect on premarital childbearing.

It is important to be aware that many of the explanatory variables will be correlated with the woman's educational choice. For instance the predicted family income, which is a positive function of the parents educational choice - among other things, will reflect the respondents' educational attainment. This is simply because there is a strong intergenerational correlation in terms of educational choice. Also the respondent's predicted wages will be positively associated with education. In fact, as is clear from table 5, the predicted wage is here a positive function of education.

In one of our specification (table 8) we include covariates that measure intergenerational effects directly. The first is a dummy variable which takes the value one if the mother of the respondent had less than 12 years of schooling. This is correlated with the women's own educational choice, so we expect this to have positive impact on the timing of the family formation process. The second variable is a dummy variable taking the value one if the mother had the first birth as a teenager, which should also have positive impact on the timing of the family formation process. Note that in this particular specification we use actual family income in 1979 instead of the predicted family income. In all other specifications the effect of these variables will feed through the predicted family income.

A variable controlling for the family structure of the respondent is also included. This simply takes the value one if the woman lived with both parents at age 14. Its purpose is to investigate the hypothesis that stressful events, such as family disruptions at young age, may affect the offspring's own family formation.

Finally, the duration until first birth is included as a covariate in the family transitions taking place after a premarital birth has taken place. The variable is important in the simulation analysis since the effects of the income variables on the initial family transitions will feed through to the subsequent transitions.

\subsection{Welfare Benefits}

We use cross variation in AFDC levels across states as a measure of the welfare generosity. 
In contrast to Rosenzweig (1999) and Hoffman and Foster (2000), the welfare generosity variable is here implemented as a non-time varying covariate ${ }^{9}$. In order to control for area specific effects, and hence improve the identification of the effect of AFDC levels on family formation behaviour, we include the county marriage rates as a covariate. Inclusion of this variable generally strengthens the effect of welfare levels on out-of-wedlock childbearing, a result that is similar to the findings by Rosenzweig (1999), as well as by Hoffman and Foster (2000). However, one should keep in mind that the county marriage rate may not serve as an ideal instrument to control for the possible endogeneity of welfare benefits as discussed in section 2

The welfare generosity variable refers to the typical AFDC payment for a two person family when the respondents' were aged 20 years old. It would be desirable to use AFDC levels that could be matched to an earlier age of the respondents, such as age 14 for instance. However, in this sample of women, where the age distribution ranges from 14 to 20 in the first year of observation, no retrospective information regarding their residence is given, a feature that makes it impossible to trace the state of residence and consequently assign AFDC levels prior to 1979.

Although a range of welfare schemes were available to the respondents during the observed period, the most common one, and by far the most substantial, were AFDC. Other welfare schemes, such as foodstamps and medical aid, followed more or less the same eligibility rules set for AFDC. The AFDC levels should therefore be a good representation of the perceived generosity level in a given state.

\section{Results}

We present parameter estimates from three different specifications. The preferred specification is reported in table 7 and includes predicted family income and time varying predicted wages in the set of covariates. The second specification (table 8 ) uses the real family income instead of the predicted levels, and include indicators for mother's education and mother's childbearing timing as covariates. The third specification (table 9) is identical to the first specification but without the sub sample of black women.

The results indicate substantial differences among the three race groups. White women marry quicker than both Hispanic and black women, whereas black women marry considerably later than Hispanic women. A reverse picture is apparent for premarital child bearing, with black women being substantially more likely to experience out-of-wedlock child bearing compared to Hispanic women, and especially white women. Once having experienced an out-of-wedlock birth, black women are considerable less likely to get married compared to the other groups, but there are no difference between the race groups in terms of having a second out-of-wedlock birth.

The family background variables have important effects on the family formation transitions. Table 8 shows that women whose mother had low educational attainment (ie. less

\footnotetext{
9 The introduction of timevarying variables (predicted wages) complicates the estimation procedure considerably. The main motivation for keeping welfare levels non-time varying was to keep the complexity of the model on a manageable level.
} 
than 12 years of schooling) or started their childbearing at a young age, tend to start the family formation earlier. It is also clear that these intergenerational effects are stronger in terms of premarital childbearing compared to marriage. The results also indicate a relatively strong association between growing up in a single parent family and premarital childbearing, although there is no effect on the timing of marriage ${ }^{10}$.

The negative AFQT parameter indicates an inverse relationship both to marriage and out-of-wedlock childbearing. This is according to our expectations, but the parameters are not generally significant at the five percent level, indicating that it is not a particularly good proxy for educational attainment. A potential problem here is that the AFQT score is positively related to the woman's earnings, implying that the effect of the AFQT is masked by the predicted wage parameter. The AFQT parameters associated with the subsequent family transitions are generally insignificant.

Women with high predicted wages are less likely to experience out-of-wedlock childbearing and they tend to delay marriage. This delaying effect on marriage is driven by the education variable included in the wage equation. Spending time in education delays marriage but increases eventually the earnings. Since this is a sample of young women the delaying effect of education is strong. Previous estimates (not shown here) where educational attainment were included as covariates directly, showed indeed that education has a strong delaying effect on marriage. It also made the predicted wage parameter become positive, as well as considerably larger. It should also be noted that the inclusion of educational attainment had dramatic effects on the AFDC parameter both in the initial transitions, as well as in the transitions following after premarital childbearing.

Given a premarital birth, we see that predicted wages have quite different effects on the consequent family formation transitions. High levels now tend to accelerate the transition into marriage, which has a strong negative effect on having a second child outside of marriage.

High family income generally delays the initiation of the family formation process, which is reflected by the strong negative coefficients both for marriage and out-of-wedlock childbearing, although it is considerable stronger for the latter. The results shows clearly that women coming from low income families are more likely to initiate the family formation process through an out-of-wedlock birth instead of marriage. A comparison of tables 7 and 8 shows that the family income parameter becomes even stronger (more negative) when the actual family income level is used instead of the predicted levels, especially for premarital childbearing. This is not unexpected since those who left the parental home prior to 1979 , and therefore more likely to experience a family formation transition, have been assigned the income of the partner as the family income. The strong downward bias reported in table 8 is generated by the fact that the income of the partner is considerably lower than the true family income of the woman.

The level of family income is also important for the family formation process after a premarital birth has taken place. The results strongly suggest that women from high income

\footnotetext{
10 This finding is consistent with Aassve at al (2000), where the family formation process is modelled as a competing risk for which the destination states are marriage and independent living, respectively. Their results show that coming from a disrupted family is posetively associated with independent living and negatively associated with marriage, although the latter association is generally quite weak.
} 
families are significantly less likely to have another birth outside marriage. The positive association between family income and marriage, although not statistically significant, suggest that women coming from high income families faces a stronger pressure to legitimise the child and therefore accelerate marriage.

The results indicate that the AFDC generosity levels are important in terms of the initiation of the family formation process. The associated parameters suggest that state welfare levels are negatively associated with marriage and positively associated with pre-marital child bearing. But the results also show that welfare generosity levels have no significant effect on the resolution of pre-marital childbearing, although the coefficients are of the expected sign. Thus having entered single motherhood, the welfare variable does not seem to have much further impact on the family formation process.

As outlined in section 4.4, the main purpose of the county marriage rates is to control for area specific effects in terms of marriage formation, and consequently out-of-wedlock childbearing ${ }^{11}$. The marriage rate parameters are positive and significant both for marriage and out-of-wedlock childbearing, and are of similar magnitude. It suggests that women who live in counties with high marriage rates tend to initiate the family formation process earlier. Failing to control for the county marriage rates (not shown here) ${ }^{12}$ reduces the magnitude of the AFDC parameter both for the marriage and the out-of-wedlock childbearing transitions. In the latter case the parameter is reduced from 0.17 to 0.13 , but is still significant. Thus controlling for area specific effects makes the AFDC parameter stronger ${ }^{13}$. However, the difference is not particularly large, and certainly not statistically significant.

In order to reveal differentials in family formation behaviour among the race groups, and consequently, differences in responses to economic incentives, we re-estimated the model without the sample of black women ${ }^{14}$. The results are given in table 9 . They show in general that white and Hispanic women are more responsive to economic incentives as far as out-of-wedlock childbearing is concerned. For instance, young white and Hispanic women from stable family background are less likely to experience this event. The association between the county marriage rate and premarital childbearing is also stronger. The economic variables also changes. For instance, white and Hispanic women are more responsive to the AFDC generosity, which confirms earlier findings (Lundberg \& Plotnick (1995)). The predicted wage rate is stronger both in terms of marriage and out-of-wedlock childbearing. The predicted family income parameter also become stronger in magnitude, although the difference is not large.

The parameter estimates for the family formation transitions after out-of-wedlock childbearing also changes. Predicted family income has a somewhat stronger effect in terms of second birth outside marriage, while the effect on marriage is weaker. Welfare generosity has no effect on subsequent transitions. The difference in terms of predicted wage is

\footnotetext{
11 This is based on the assumption that high marriage rates translates into lower rates of out-of-wedlock childbearing. 12 These results are available from the author on request.

13 This result is in line with the finding by Rosenzweig (1999) and Duncan and Foster (2000), who both shows that the effect of AFDC on premarital childbearing becomes stronger when state and cohort fixed effects are controlled for.

14 Re-estimation on black women only would be desireable, but this was not possible due to the relatively small sample black women.
} 
more noticeable. A comparison of tables 9 and 7 shows that the strong negative effect of predicted wage on second birth outside marriage has almost disappeared. This is an interesting results, since it suggest that there is hardly any disincentive effect from high wages on having a second birth outside marriage among white and Hispanic women.

The inclusion of unobserved heterogeneity has a relatively strong impact on the parameter results, especially for the shape parameters of the hazard function. Without this control the negative duration dependence becomes considerably stronger in all transitions ${ }^{15}$. In the first set of transitions, 77.8 percent of the sample is characterised as movers (the masspoint is around 0.5 ), whereas the remaining 22.2 percent are assigned a large negative masspoint of -1.74 . After a premarital birth has taken place, the percentages of movers and stayers are 38.3 and 61.7, respectively.

Although interpretation of the unobserved heterogeneity terms is not straight forward, the estimated masspoints do lend themselves to a convenient explanation regarding the transition to marriage from single motherhood. This is rooted in the fact that we are not distinguishing between single mothers who goes on to marry the true father of the child, from those who do not ${ }^{16}$. Consequently the masspoints are likely to identify partners who prior to the childbirth had relatively strong intensions of marrying, from those who had less established partnerships. In the former case, we might expect a premarital pregnancy to accelerate the marriage transition in order to legitimise the child. This will be reflected by a positive value of $v^{17}$. The negative value of $v$, on the other hand, will reflect women who delay marriage after having experienced a premarital birth. These women were likely to be in less stable relationships when childbearing took place, and are, therefore, less likely to marry the biological father of the child.

\section{Sensitivity analysis}

The highly nonlinear nature of the our model implies that the parameter estimates are not necessarily very informative in terms of assessing changes in behaviour from changes in the explanatory variables. This means that sensitivity analysis of the parameters cannot be undertaken in a satisfactory fashion without the help of simulations.

The synthetic transition histories, from which the simulated descriptive statistics are computed, are generated by re-sampling the women in our NLSY sample five times. We compute three separate statistics which adequately describes behaviour associated with outof-wedlock childbearing. These are the number of out-of-wedlock births as a percentage of the total number of first births, the mean time spent as a single mother, and the number of women marrying, again measured as a percentage of women experiencing a premarital

\footnotetext{
15 The specifications wihout unobserved heterogenetiy are not reported here, but are available from the author on request.

16 It would be advantageous to model transitions from single motherhood to marriage as two possible destinations, the first being marriage to the biological father, and the second as marriage to someone that is not the father of the child. However, having two destinations to marriage, in addition to having a second child outside marriage, is a non-trivial extension of the model and was beyond the scope of the current analysis.

17 Evidence of this effect is reported in Lillard et al (1999). They show that the event of a premarital birth increases the the risk of marriage.
} 
Table 7: Specification with predicted wages and predicted family income as covariates. A1, A2, and A3 are slope parameters of the hazard function. Standard errors in parenthesis.

\begin{tabular}{|c|c|c|c|c|}
\hline \multirow[b]{3}{*}{ Covariates } & \multicolumn{4}{|c|}{ Transitions $1 \rightarrow 2 \& 1 \rightarrow 3:$} \\
\hline & \multicolumn{2}{|c|}{$\begin{array}{l}\text { First marriage } \\
\text { before 1st birth }\end{array}$} & \multicolumn{2}{|c|}{$\begin{array}{c}\text { First birth } \\
\text { before marriage }\end{array}$} \\
\hline & Coeff. & Std. Err. & Coeff. & Std. Err. \\
\hline Intercept & -3.592 & $(0.266)$ & -2.973 & $(0.316)$ \\
\hline White & 0.215 & $(0.074)$ & -0.331 & $(0.112)$ \\
\hline Black & -0.814 & $(0.100)$ & 0.937 & $(0.110)$ \\
\hline Lived with both parents at age 14 & 0.052 & $(0.072)$ & -0.314 & $(0.079)$ \\
\hline Marriage rate at county level & 0.371 & $(0.142)$ & 0.380 & $(0.177)$ \\
\hline AFQT score & -0.327 & $(0.185)$ & -0.184 & $(0.258)$ \\
\hline Welfare generosity & -0.096 & $(0.029)$ & 0.175 & $(0.037)$ \\
\hline Predicted family income & -0.408 & $(0.041)$ & -0.739 & $(0.054)$ \\
\hline Predicted wage rate & -0.691 & $(0.243)$ & -0.576 & $(0.263)$ \\
\hline A1 & 7.658 & $(0.354)$ & 5.183 & $(0.338)$ \\
\hline A2 & 1.503 & $(0.174)$ & 0.158 & $(0.239)$ \\
\hline A3 & 0.066 & $(0.346)$ & 0.699 & $(0.508)$ \\
\hline Masspoint 1 [Probability 1] & & 0.496 & {$[0.778]$} & \\
\hline \multirow[t]{3}{*}{ Masspoint 2 [Probability 2] } & & -1.742 & [0.222] & \\
\hline & \multicolumn{4}{|c|}{ Transitions $3 \rightarrow 4$ \& $3 \rightarrow 5:$} \\
\hline & \multicolumn{2}{|c|}{$\begin{array}{l}\text { First marriage } \\
\text { after 1st birth }\end{array}$} & \multicolumn{2}{|c|}{$\begin{array}{c}\text { Second birth } \\
\text { before marriage }\end{array}$} \\
\hline Covariates & Coeff. & Std.Err. & Coeff. & Std.Err. \\
\hline Intercept & -0.988 & $(0.517)$ & -1.420 & $(0.527)$ \\
\hline White & 0.243 & $(0.159)$ & -0.152 & $(0.184)$ \\
\hline Black & -0.844 & $(0.166)$ & 0.238 & $(0.174)$ \\
\hline Marriage rate at county level & 0.178 & $(0.287)$ & 0.281 & $(0.271)$ \\
\hline AFQT score & 0.348 & $(0.424)$ & -0.346 & $(0.411)$ \\
\hline Duration until first birth & -0.703 & $(0.234)$ & -0.596 & $(0.225)$ \\
\hline Welfare generosity & -0.089 & $(0.063)$ & 0.083 & $(0.059)$ \\
\hline Predicted family income & 0.796 & $(0.899)$ & -0.238 & $(0.086)$ \\
\hline Predicted wage rate & 0.766 & $(0.571)$ & -1.310 & $(0.548)$ \\
\hline$\overline{\mathrm{A} 1}$ & 6.662 & $(1.139)$ & 13.319 & $(1.421)$ \\
\hline A2 & 2.224 & $(1.225)$ & -1.464 & $(1.092)$ \\
\hline A3 & -1.505 & $(0.560)$ & -1.280 & $(0.440)$ \\
\hline Masspoint 1 [Probability 1] & & 1.985 & [0.383] & \\
\hline Masspoint 2 [Probability 2] & & -1.233 & [0.617] & \\
\hline $\mathrm{N}=3715, \operatorname{LogLik}=-5539.1$ & & & & \\
\hline
\end{tabular}


Table 8: Specification with real family income in 1978 instead of predicted family income. A1, A2, and A3 are the slope parameters of the hazard function. Standard errors in parenthesis.

\begin{tabular}{|c|c|c|c|c|}
\hline \multirow[b]{3}{*}{ Covariates } & \multicolumn{4}{|c|}{ Transitions $1 \rightarrow 2 \& 1 \rightarrow 3$ : } \\
\hline & \multicolumn{2}{|c|}{$\begin{array}{l}\text { Marriage before } \\
\text { childbearing }\end{array}$} & \multicolumn{2}{|c|}{$\begin{array}{c}\text { First birth } \\
\text { before marriage }\end{array}$} \\
\hline & Coeff. & Std. Err. & Coeff. & Std. Err. \\
\hline Intercept & $-4,364$ & $(0,285)$ & $-4,218$ & $(0,346)$ \\
\hline White & 0,232 & $(0,076)$ & $-0,270$ & $(0,117)$ \\
\hline Black & $-0,849$ & $(0,101)$ & 0,874 & $(0,114)$ \\
\hline Lived with both parents at age 14 & $-0,011$ & $(0,071)$ & $-0,354$ & $(0,079)$ \\
\hline Mother had first birth when teenager & 0,375 & $(0,064)$ & 0,607 & $(0,079)$ \\
\hline Mother has less than 12 years of schooling & 0,378 & $(0,062)$ & 0,681 & $(0,082)$ \\
\hline Marriage rate at county level & 0,313 & $(0,144)$ & 0,333 & $(0,187)$ \\
\hline AFQT score & $-0,260$ & $(0,184)$ & $-0,122$ & $(0,259)$ \\
\hline Welfare generosity & $-0,138$ & $(0,029)$ & 0,127 & $(0,038)$ \\
\hline Real family income in 1978 & $-0,797$ & $(0,158)$ & $-2,689$ & $(0,264)$ \\
\hline Predicted wage rate & $-0,698$ & $(0,239)$ & $-0,521$ & $(0,282)$ \\
\hline A1 & 7,747 & $(0,356)$ & 5,166 & $(0,332)$ \\
\hline A2 & 1,521 & $(0,163)$ & 0,283 & $(0,233)$ \\
\hline A3 & 0,086 & $(0,352)$ & 0,582 & $(0,504)$ \\
\hline Masspoint 1 [Probability 1] & & 0,508 & {$[0,779]$} & \\
\hline \multirow[t]{3}{*}{ Masspoint 2 [Probability 2] } & & $-1,787$ & {$[0,221]$} & \\
\hline & \multicolumn{4}{|c|}{ Transitions $3 \rightarrow 4 \& 3 \rightarrow 5$ : } \\
\hline & \multicolumn{2}{|c|}{$\begin{array}{l}\text { Marriage after } \\
\text { first birth }\end{array}$} & \multicolumn{2}{|c|}{$\begin{array}{c}\text { Second birth } \\
\text { before marriage }\end{array}$} \\
\hline Covariates & Coeff. & Std.Err. & Coeff. & Std.Err: \\
\hline Intercept & $-0,950$ & $(0,522)$ & $-1,484$ & $(0,535)$ \\
\hline White & $-0,209$ & $(0,183)$ & 0,103 & $(0,195)$ \\
\hline Black & $-0,816$ & $(0,166)$ & 0,209 & $(0,172)$ \\
\hline Marriage rate at county level & 0,169 & $(0,291)$ & 0,289 & $(0,280)$ \\
\hline AFQT score & 0,387 & $(0,427)$ & $-0,387$ & $(0,417)$ \\
\hline Duration until first birth & $-0,722$ & $(0,235)$ & $-0,592$ & $(0,228)$ \\
\hline Welfare generosity & $-0,081$ & $(0,063)$ & 0,072 & $(0,059)$ \\
\hline Real family income in 1978 & 0,508 & $(0,374)$ & $-0,969$ & $(0,435)$ \\
\hline Predicted wage rate & 0,792 & $(0,566)$ & $-1,470$ & $(0,541)$ \\
\hline A1 & 6,544 & $(1,158)$ & 13,131 & $(1,437)$ \\
\hline A2 & 2,188 & $(1,241)$ & $-1,456$ & $(1,105)$ \\
\hline A3 & $-1,523$ & $(0,561)$ & $-1,226$ & $(0,446)$ \\
\hline Masspoint 1 [Probability 1] & & 1,965 & {$[0,382]$} & \\
\hline Masspoint 2 [Probability 2] & & $-1,216$ & {$[0,618]$} & \\
\hline
\end{tabular}


Table 9: Specification without subsample of black women, with predicted wages and predicted family income. A1, A2, and A3 are the slope parameters of the hazard function. Standard errors in parenthesis.

\begin{tabular}{|c|c|c|c|c|}
\hline \multirow[b]{3}{*}{ Covariates } & \multicolumn{4}{|c|}{ Transitions $1 \rightarrow 2 \& 1 \rightarrow 3:$} \\
\hline & \multicolumn{2}{|c|}{$\begin{array}{l}\text { First marriage } \\
\text { before 1st birth }\end{array}$} & \multicolumn{2}{|c|}{$\begin{array}{c}\text { First birth } \\
\text { before marriage }\end{array}$} \\
\hline & Coeff. & Std. Err. & Coeff. & Std. Err. \\
\hline Intercept & $-3,379$ & $(0,277)$ & $-2,943$ & $(0,461)$ \\
\hline White & 0,235 & $(0,074)$ & $-0,237$ & $(0,114)$ \\
\hline Lived with both parents at age 14 & 0,041 & $(0,081)$ & $-0,572$ & $(0,117)$ \\
\hline Marriage rate at county level & 0,387 & $(0,154)$ & 0,660 & $(0,257)$ \\
\hline AFQT score & -0.332 & $(0.197)$ & -0.148 & $(0.366)$ \\
\hline Welfare generosity & $-0,098$ & $(0,031)$ & 0,201 & $(0,052)$ \\
\hline Predicted family income & $-0,425$ & $(0,044)$ & $-0,856$ & $(0,078)$ \\
\hline Predicted wage rate & $-0,742$ & $(0,253)$ & $-0,662$ & $(0,303)$ \\
\hline A1 & 7,417 & $(0,369)$ & 5,142 & $(0,506)$ \\
\hline $\mathrm{A} 2$ & 1,415 & $(0,189)$ & 0,428 & $(0,313)$ \\
\hline A3 & 0,065 & $(0,372)$ & 0,299 & $(0,805)$ \\
\hline Masspoint 1 [Probability 1] & & 0,451 & {$[0,795]$} & \\
\hline \multirow[t]{3}{*}{ Masspoint 2 [Probability 2] } & & $-1,752$ & {$[0,205]$} & \\
\hline & \multicolumn{4}{|c|}{ Transitions $3 \rightarrow 4 \&$ \& $\rightarrow$ : } \\
\hline & \multicolumn{2}{|c|}{$\begin{array}{l}\text { First marriage } \\
\text { after 1st birth }\end{array}$} & \multicolumn{2}{|c|}{$\begin{array}{c}\text { Second birth } \\
\text { before marriage }\end{array}$} \\
\hline Covariates & Coeff. & Std.Err. & Coeff. & Std.Err. \\
\hline Intercept & $-1,002$ & $(0,649)$ & $-1,789$ & $(0,841)$ \\
\hline White & 0,268 & $(0,167)$ & $-0,073$ & $(0,197)$ \\
\hline Marriage rate at county level & 0,462 & $(0,361)$ & 0,816 & $(0,500)$ \\
\hline AFQT score & 0,720 & $(0,714)$ & $-0,732$ & $(0,698)$ \\
\hline Duration until first birth & $-0,814$ & $(0,307)$ & $-0,662$ & $(0,379)$ \\
\hline Welfare generosity & $-0,051$ & $(0,082)$ & 0,085 & $(0,095)$ \\
\hline Predicted family income & 0,313 & $(1,171)$ & $-0,354$ & $(0,129)$ \\
\hline Predicted wage rate & 0,762 & $(0,714)$ & $-0,418$ & $(0,853)$ \\
\hline A1 & 5,948 & $(1,600)$ & 12,263 & $(2,050)$ \\
\hline A2 & 0,915 & $(1,678)$ & $-1,622$ & $(1,829)$ \\
\hline A3 & $-1,357$ & $(0,840)$ & $-1,438$ & $(0,871)$ \\
\hline Masspoint 1 [Probability 1] & & 1,747 & {$[0,419]$} & \\
\hline Masspoint 2 [Probability 2] & & $-1,262$ & {$[0,581]$} & \\
\hline $\mathrm{N}=3715, \operatorname{LogLik}=-3890.53$ & & & & \\
\hline
\end{tabular}


birth. These statistics are then computed for different values of predicted wages, predicted family income, and the level of welfare generosity (AFDC). As can be seen from figures 2 - 6 these levels are denoted as percentages from their original level. For instance, where the $\mathrm{x}$-axis takes the value 0.6 the corresponding variable value is 60 percent more than the original level. Likewise, at the axis value of -0.6 the original level has been reduced by 60 percent. The midpoint of the axis, which is zero, refers to the original level as given by the sample data.

The simulation analysis is also useful for assessing the fit of the empirical model, since the synthetic transitions histories can be compared to the ones in the sample. A comparison of this sort is undertaken in table 4 where the simulated values are given in brackets. It shows that the overall fit is quite good, and that the model is able to replicate the sample histories in a satisfactory way, especially for white women. Slightly higher deviations are apparent among the sub-sample of Hispanic and black women, which of course is due to smaller sample sizes for these two groups. Also the model is considerable better in predicting family histories of high frequencies, especially for the histories $1 \cdot 2 \cdot 4 \cdot 6$ and $1 \cdot 3 \cdot 5$.

Figure 2 shows how the proportion of out-of-wedlock childbearing varies with different levels of predicted wages and welfare generosity. It shows a remarkable linear relationship, where the effect of welfare benefits dominates the effect due to different levels of predicted wages. This results is not surprising, since the negative predicted wage parameter is of roughly the same magnitude for both premarital child bearing and marriage. So as predicted wages increase, less women experience out-of-wedlock childbearing. But at the same time less women marry, increasing the proportion of women being at risk of having a birth outside marriage. The net effect is therefore small, as can be seen from picture 2 . The AFDC levels, on the other hand, are positively associated with premarital childbearing, and negatively associated with marriage, and has therefore a much larger effect on the proportion of women having children outside marriage.

The response surface for black women (figure 3) is similar to that of white women, although here the pattern is more non-linear and slightly more responsive to differences in predicted wage levels, although the welfare effect still clearly dominates. More important is the difference in the overall levels of premarital childbearing among white and black women. For black women the range of premarital childbearing is from 50 percent to 65 percent, compared to the maximum level among white women, which is as low as 32 percent.

Figure 4 shows simulated percentages of premarital childbearing as functions of predicted family income and predicted wages. Also here we see that predicted wages has little effect, whereas the level of predicted family income has a strong impact. The latter is driven by the fact that the negative family income parameter with respect to pre-marital childbearing is twice the size of the parameter associated with the transition into marriage. A similar pattern is evident for Black women (not shown here) with an equally important effect of predicted family income.

Figure 5 shows the surface of simulated percentages of white single mothers who marry before the end of the censoring date as a function of predicted wages and AFDC welfare benefits. In order to assess this relationship first recall that predicted wages are positively associated with marriage, while AFDC levels have a negative effect. In addition the dura- 


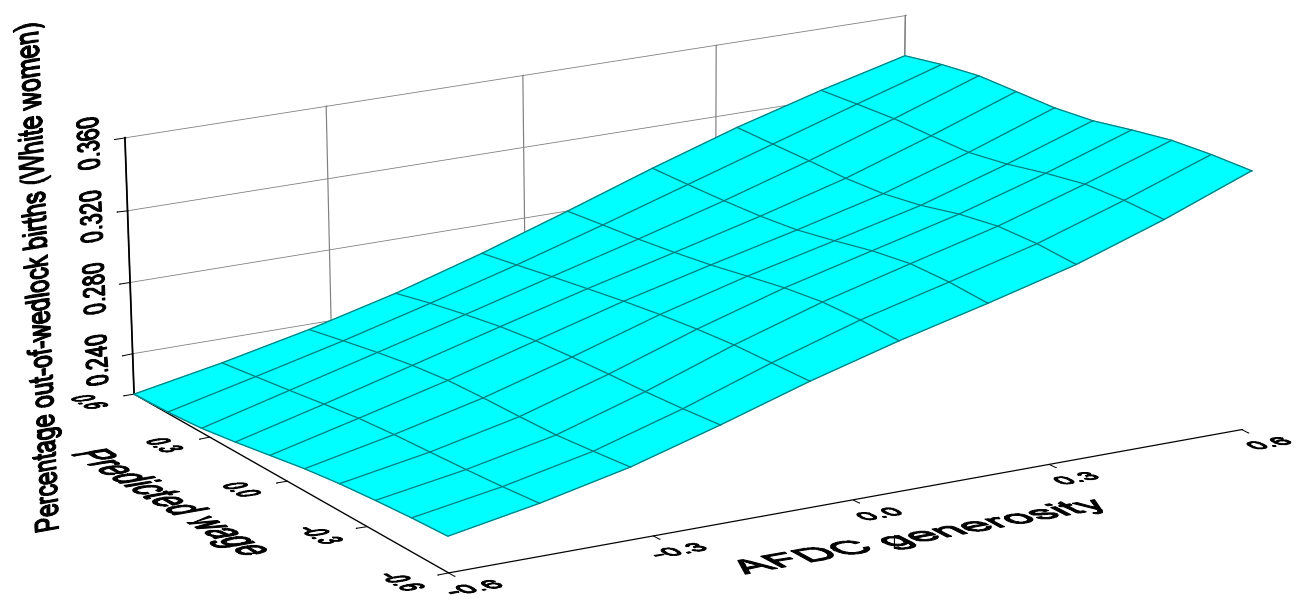

Figure 2: Simulated percentages of out-of-wedlock childbearing as a function of predicted wages and AFDC generosity levels for white women. 


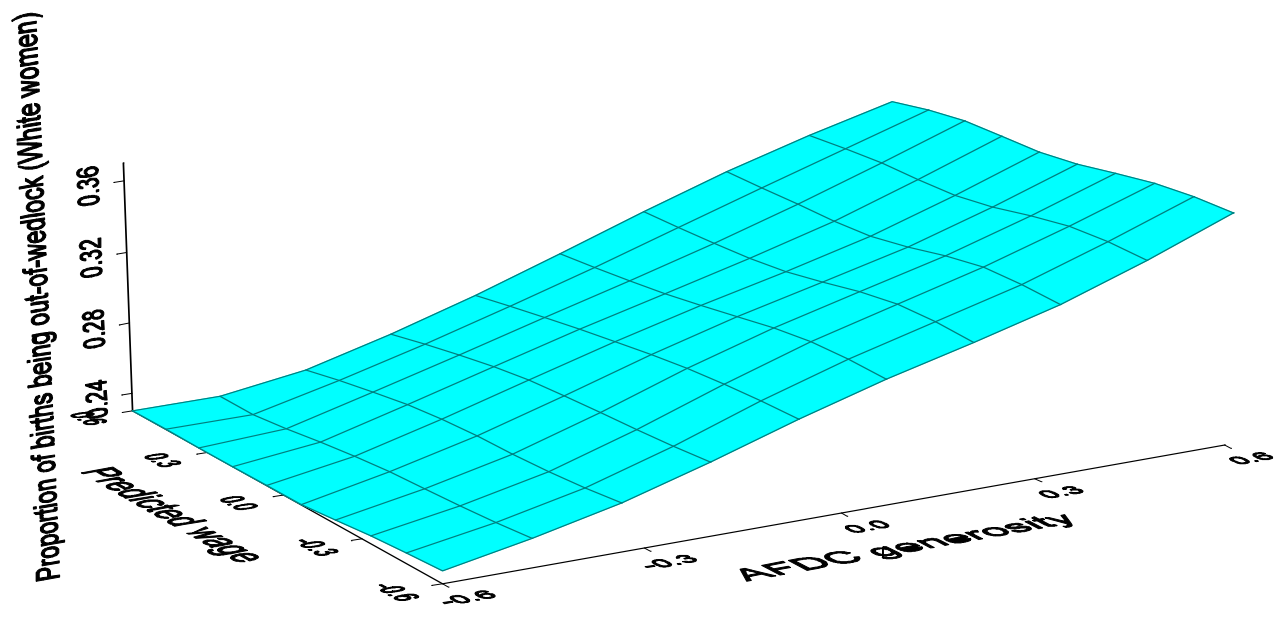

Figure 3: Simulated percentages of out-of-wedlock childbearing as a function of predicted wages and AFDC generosity levels for black women. 


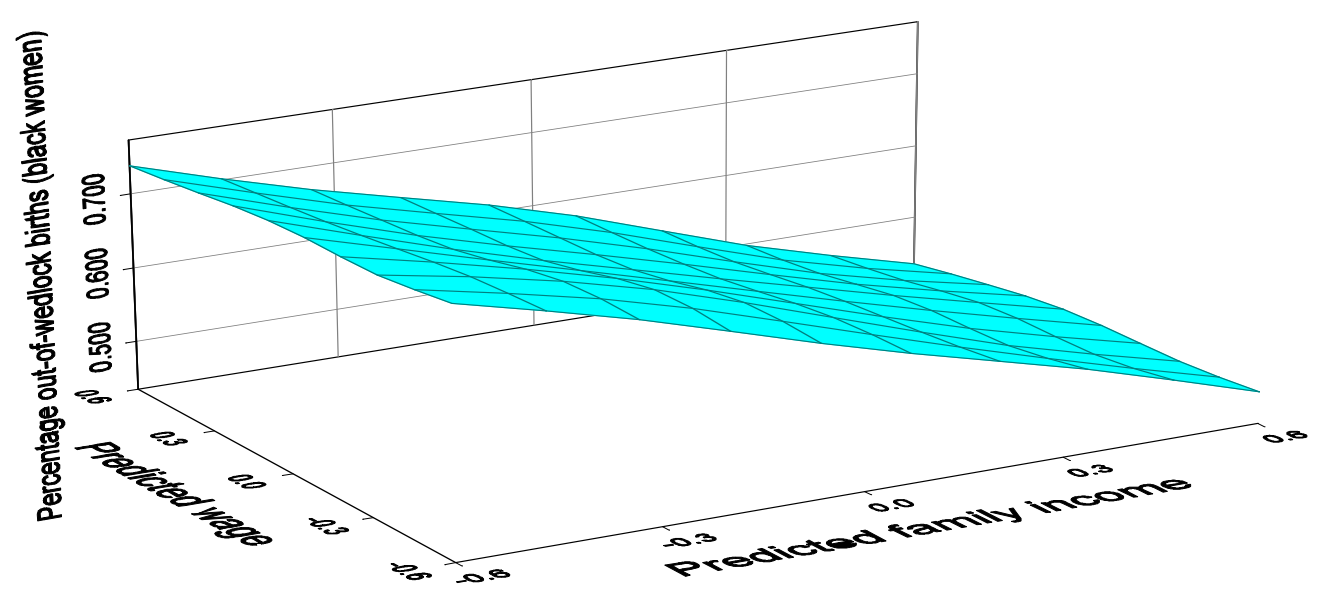

Figure 4: Simulated percentages of out-of-wedlock childbearing as a function of predicted wages and predicted family income for black women. 
tion until first birth (i.e. the age) is negatively associated with marriage. This latter variable is of course affected by predicted wages and AFDC levels in the initial family transition. For instance high levels of predicted wages will delay first premarital birth, which in turn reduces the likelihood of marriage when being a single mother. There is consequently an indirect and negative effect of predicted wages that will reduce the positive direct effect. The same mechanism will be present in terms of welfare generosity, although here the effects will work in opposite directions. In neither case is the net effect easy to foresee without the simulations. Picture 5 represents the net effect of these opposing forces. The shape of the graph, although highly non-linear, suggest that the direct effects of the predicted wage and AFDC levels dominate the indirect dynamic effect. This must be the case since the marriage rate is highest when predicted wages are high and AFDC levels are low. Likewise, the marriage rate is at the lowest when predicted wages are low and AFDC levels are high.

Figure 6 shows the response surface of the mean time spent as a single mother as a function of predicted wages and predicted family income. It reveals a highly non-linear and complex pattern. This is not entirely unexpected since our descriptive statistic now also depends on the time dimension, as well as the incidence rate. The picture shows that several combinations of predicted wages and predicted family income can reduce the time spent as a single mother. The lowest level (2.73 years) is produced when both variables are given low values (lower right hand corner). But low levels of this statistic are also achieved when the predicted wage is assigned a high value together with a low value of predicted family income.

Starting in the lower left hand corner where predicted wage is at the maximum level and predicted family income is at its lowest level, we can analyse the effects as the predicted wage decreases, keeping the predicted family income constant at the low level. As the predicted wages are reduced, the mean time spent as a single mother increases until the predicted wage level is at the original level, but then starts to fall. This decline, inconsistent with the positive predicted wage parameters, is caused by the dynamic duration variable which is negatively associated with marriage from single motherhood.

However, the pattern is dependent upon the level of predicted family income. For instance when predicted family income is at the original level, the longest time spent as a single mother is produced when predicted wage is reduced by thirty percent. When the predicted family income is thirty percent higher than the original level, then the longest duration is produced when the predicted wage is thirty percent lower than the original level.

\section{Concluding remarks}

This study, using data from the NLSY, has provided further evidence that young women's economic resources are important in the analysis of young people's family formation behaviour. The findings suggest that both personal economic resources and family resources, as well as welfare benefits, are important in explaining out-of-wedlock childbearing. In particular we found that women from wealthy families tend to delay the family formation process in general and were less likely to experience out-of-wedlock childbearing. We also 


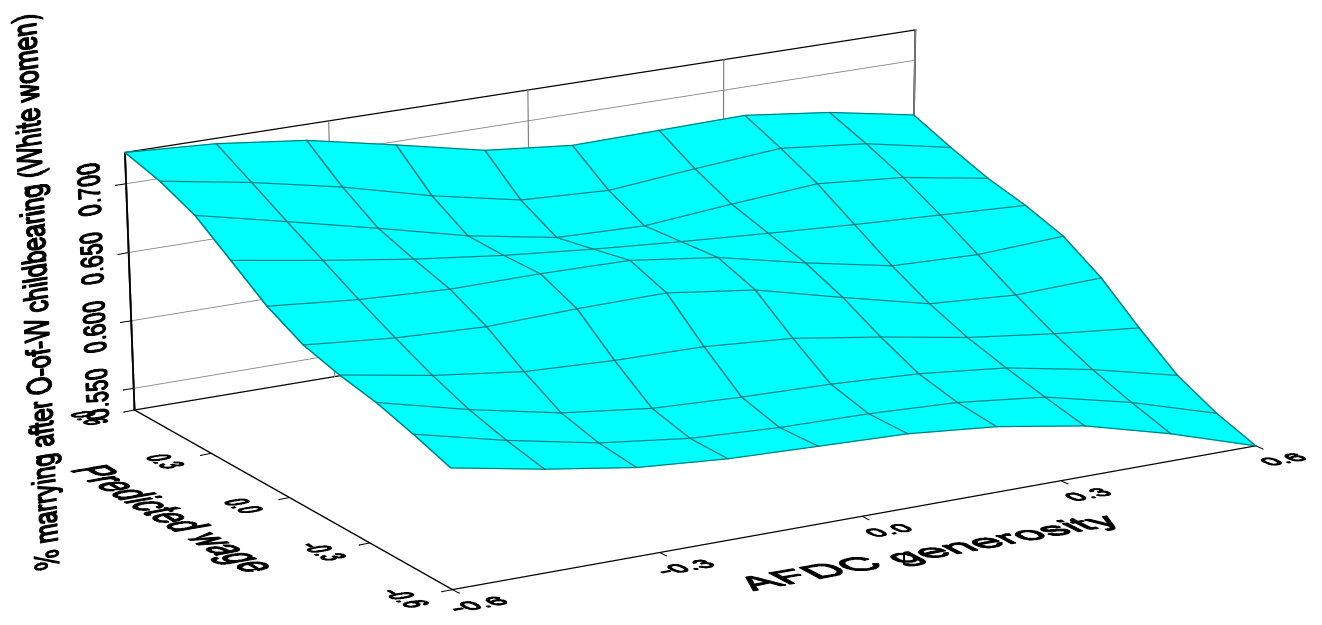

Figure 5: Simulated percentages of white single mothers marrying before censoring date. 


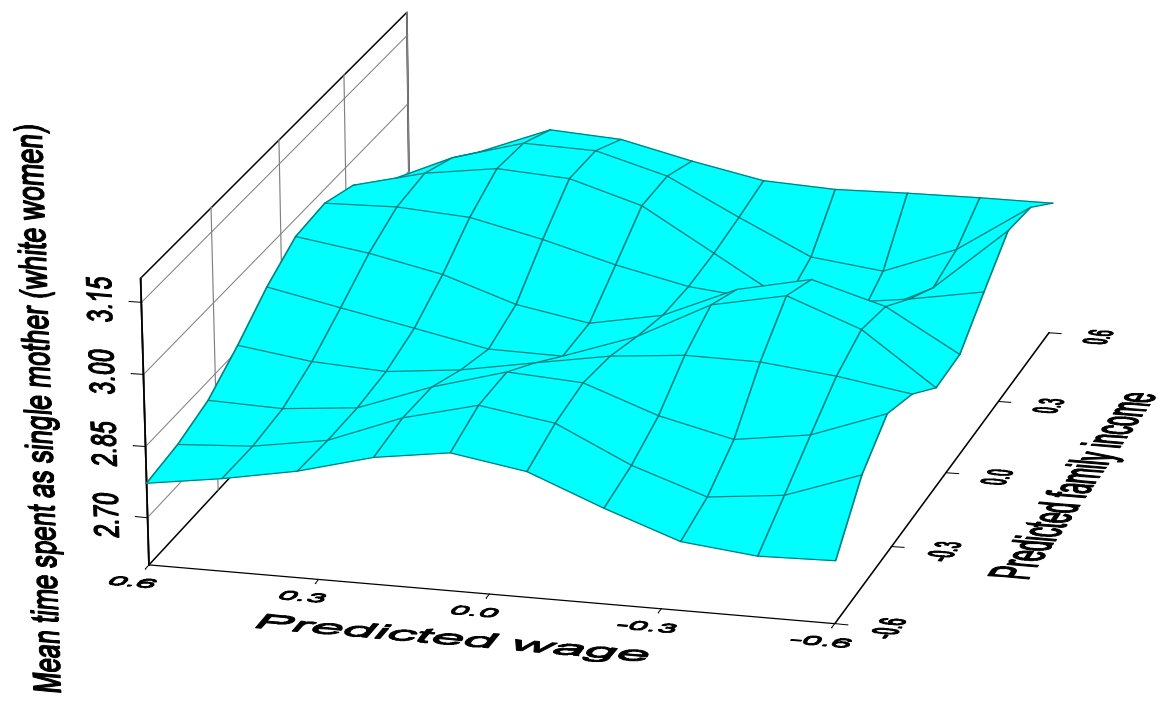

Figure 6: Simulated mean time spent as a single mother as function of predicted wage rates and predicted family income, white women. 
found that women with high earning potential delayed the family formation process. Generous welfare benefits seemed to increase the likelihood of becoming a single mother.

However, when a premarital birth has taken place the effect of these economic resources changes. Welfare generosity, for instance, does not appear to be of any great importance after the woman has entered single motherhood. The predicted wage level, on the other hand, becomes more important: women with high earnings potential marry quicker and are considerably less likely to have a second out-of-wedlock birth. The predicted family income, having a strong negative effect both on first marriage and premarital childbearing, has only a modest effect after premarital birth has taken place.

The simulation analysis provided insights into the process of out-of-wedlock childbearing that could not easily be derived from the parameter estimates. For instance, although women's predicted wages are found to be negatively and statistically significant with respect to pre-marital childbearing, they have almost no practical significance compared to predicted family income as the two variables are varied. Also welfare income seemed to have a stronger effect than predicted wages. For family formation events taking place after out-of-wedlock childbearing, our simulations showed that the effect of economic resources are highly non-linear and difficult to predict from the parameter estimates alone. For instance, in terms of the mean time spent as a single mother we showed that this could be minimised through several combinations of the variables capturing economic resources.

\section{References}

[1] Aassve, A.,Burgess, S., Chesher, A. and Propper, C., (2000), "Transitions From Home to Marriage among Young American Women", mimeo

[2] Aassve, A., (2000), ”An Econometric Analysis of Family Formation”, Unpublished PhD Thesis, University of Bristol

[3] Abrahamse, A., Morrison, P. and Waite, L., (1988), "Beyond Stereotypes: Who Becomes a Single Mother?", RAND Report no. R-3489-HHS/NICHD.

[4] An. C, Haveman, R. and Wolfe, B., (1993), "Teen Out-of-Wedlock Births and Welfare Receipt: The Role of Childhood Events and Economic Circumstances", The Review of Economics and Statistics, LXXV:195-207

[5] Antel, J. J., (1992), "The Intergenerational Transfers of Welfare Dependency: Some Statistical Evidence", The Review of Economics and Statistics, 74:467-473

[6] Becker, G., (1965), "A Theory of Allocation of Time", Economic Journal, 75:493-517

[7] Becker, G., (1973), "A Theory of Marriage: Part I", Journal of Political Economy, 81:813846

[8] Becker, G., (1991), "A Treatise on the Family", Enlarged edition, Cambridge, Mass.: Harvard University Press.

[9] Becker, G. and Lewis, H. G., (1973), "On the Interaction between Quantity and Quality of Children", Journal of Political Economy, 81: s143-s162

[10] van den Berg, G., (2000), "Duration Models: Specification, Identification, and Multiple Durations", In Handbook of Econometrics, Volume V, edited by James J. Heckman and Edward Leamer, Amsterdam: Elsevier Sci. 
[11] Brien, M. J., (1997), "Racial Differences in Marriage and the Role of Marriage Markets”, Journal of Human Resources, 32:741-778

[12] Brien, M., Lillard, L. and Waite, L., (1999), "Interrelated Family-Building Behaviors: Cohabitation, Marriage, and Non-Marital Conception”, Demography, 36:535-551

[13] Cigno, A. and Ermisch, J., (1989), "A Microeconomic Analysis of the Timing of Births", European Economic Review, 33:737-760

[14] Cole, N. and Currie, J., (1994), "Reported Income in the NLSY: Consistency Checks and Methods of Cleaning the Data", NBER Technical Working Paper.

[15] Cooksey, E., (1990), "Factors in the Resolution of Adolescent Premarital Pregnancies", Demography, 27:207-218

[16] Duncan, G. J. and Hoffman, S. D., (1990), "Welfare Benefits, Economic Opportunities and the Incidence of Out-of-Wedlock Births among Black Teenage Girls", Demography, 27:519-557

[17] Ermisch, J., (1989), "Purchased Child Care, Optimal Family Size and Mother's Employment: Theory and Econometric Analysis”, Journal of Population Economics, 2:79-102

[18] Hanson, S. L., Myers, D. E. and Ginsburg, A. L., (1987), "The Role of Responsibility and Knowledge in Reducing Teenage Out-of-Wedlock Childbearing”, Journal of Marriage and the Family, 49:241-256

[19] Heckman, J.J. and Singer, B., (1984), "A Method for Minimising the Impact of Distributional Assumptions in Econometric Models for Duration Data”, Econometrica, 52:271-290

[20] Hoffman, S. and Foster, E., (2000), "AFDC Benefits and Nonmarital Births to Young Women", Journal of Human Resources, 35.

[21] Lancaster, T., (1990), "The econometric Analysis of Transition Data”, CUP, Cambridge

[22] Lundberg, S. and Plotnick, R., (1995), "Adolescent Premarital Childbearing: Do Economic Incentives Matter?", Journal of Labour Economics, 13:177-200

[23] Mincer, J., (1974), "Schooling, Experience and Earnings", New York: Columbia University Press.

[24] Newman, J. L. and McCulloch, C. E., (1984), "A Hazard Rate Approach to the Timing of Births", Econometrica, 52:939-961

[25] Rosenzweig, M, (1999), "Welfare, Marital Prospects, and Nonmarital Childbearing”, Journal of Political Economy, 107:S3-S32

[26] South, S. J., (1996), "Mate Availablitity and the Transition to Unwed Motherhood: A Paradox of Population Structure", Journal of Marriage and the Family, 58:265-279

[27] South, S. J. and Lloyd, K. M., (1992), "Marriage Markets and Non-Marital Fertility in the United States", Demography, 29:247-264

[28] Yamaguchi, K. and Kandel, D., (1987), "Drug Use and Other Determinants of Premarital Pregnancy and Its Outcome: A Dynamic Analysis of Competing Life Events”, Journal of Marriage and the Family, 49:257-270.

[29] Willis, R. J., (1999), "A Theory of Out-of-Wedlock Childbearing”, Journal of Political Economy, 107:S33-S64

] 


\section{Appendix A. Econometric analysis}

This section outlines the econometric model based on the structure of the family formation process outlined earlier. In this model we define continuously distributed latent variates $T_{i j}^{r}$ associated with the risk at the $r$ th transition of moving from state $i$ to state $j$, with $i, j \in$ $\mathcal{S}=\{1,2,3,4,5,6\}, r \in\{1,2,3, \ldots\}$. The conditional distributions (given covariates to be introduced shortly) of the variates $T_{i j}^{r}$ are denoted by distribution functions $F_{i j}^{r}(\cdot \cdot \cdot)$ with associated hazard functions denoted by:

$$
h_{i j}^{r}\left(s \mid x(s), v^{r}\right) \quad i, j \in\{1,2,3,4,5,6\}, r \in\{1,2,3, \ldots\}
$$

where $x(s)$ is a vector of covariates, some of which may be time varying, and $v^{r}$ is a realisation of a transition number specific time invariant random variable, $V^{r}$, included to capture the influence of unmeasured covariates varying across individuals and assumed to be distributed independently of the observed covariates. The corresponding conditional integrated hazard functions are denoted by

$$
I_{i j}^{r}\left(t \mid x(t), v^{r}\right)=\int_{0}^{t} h_{i j}^{r}\left(s \mid x(s), v^{r}\right) d s .
$$

In this competing risks model transition $r$ from state $i$ to state $k$ is regarded as occurring if $T_{i k}^{r}=\min _{j \neq i, j \in \mathcal{S}}\left(T_{i j}^{r}\right)$. Accordingly the probability of exit from state $i$ to state $k$ at transition $r$ in the age interval $(t, t+d t)$ conditional on observed and unobserved covariates is (see e.g. Lancaster(1990)):

$$
h_{i k}^{r}\left(t \mid x(t), v^{r}\right) \exp \left(-\sum_{j=1}^{k} I_{i j}^{r}\left(t \mid x(t), v^{r}\right)\right) d t .
$$

The likelihood function is specified accordingly. First note that women are observed from age $t^{0}$ (here age 13) until first entry into state 5 and 6 , or until age $c$ after which the event history is censored. Let $R \geq 0$ be the number of transitions made by an individual, $t^{r}$ be age at transition $r, z^{r}=\min \left(t^{r}, c\right)-t^{r-1}, 1<r \leq R$, and let $1_{[\mathcal{C}]}=1$ if $\mathcal{C}$ is true and 0 otherwise. The log likelihood contribution for an individual making $R$ transitions with state occupancy history $\left(i_{1}, i_{2}, i_{3}, \ldots, i_{R+1}\right)$ and transitions at ages $\left(t^{1}, t^{2}, t^{3}, \ldots, t^{R}\right)$, time $z^{r}$ being the time spent in state $i_{r}$, conditional on observed and unobserved covariates is

$$
L=\sum_{r=1}^{R}\left(1_{\left[t^{r}<c\right]} \log h_{i_{r} i_{r+1}}^{r}\left(z^{r} \mid x\left(z^{r}\right), v^{r}\right)-\sum_{j=1}^{k} I_{i_{r} j}^{r}\left(z^{r} \mid x\left(z^{r}\right), v^{r}\right)\right)
$$

Note that all individuals start in state $i_{1}=1$ and that all event histories are either right censored or end with $i_{R+1}=[5,6]$. The likelihood contribution conditional on observed covariates alone is the expectation of the likelihood contribution, given by integrating the previous expression, with respect to the distribution of $V^{r}$.

A variety of patterns of duration dependence in the hazard function is accommodated by using a continuous piecewise linear functional form for the log hazard functions with two knots, as employed by Newman and McCulloch. For $b>a$ let

$$
A(t, a, b)=\max (0, \min (t, b)-a)
$$


then the hazard function associated with passage from state $i$ to state $j$ at transition $r$ is $h_{i j}^{r}(t)=\exp \left(x(t)^{\prime} \beta_{i j}^{r}+\alpha_{1 i j}^{r} A\left(t, 0, w_{1}\right)+\alpha_{2 i j}^{r} A\left(t, w_{1}, w_{2}\right)+\alpha_{3 i j}^{r} A\left(t, w_{2}, \infty\right)+\gamma^{r} v^{r}\right)$ in which $r \in\{1,2,3, \ldots\}$, depending on whether allowance is made for across individual heterogeneity and if so whether a univariate or bivariate specification is employed. For example for $t>w_{2}$ the hazard function is

$$
h_{i j}^{r}(t)=\exp \left(x(t)^{\prime} \beta_{i j}^{r}+\alpha_{1 i j}^{r} w_{1}+\alpha_{2 i j}^{r}\left(w_{2}-w_{1}\right)+\alpha_{3 i j}^{r} t+\gamma^{r} v^{r}\right) .
$$

The knot locations, $w_{2}$ and $w_{1}$, are fixed a priori. For $r=1, w_{2}=13$ and $w_{1}=6$ (corresponding to ages 28 and 19). For $r=2, w_{2}=5$ and $w_{1}=3$. The parameters $\alpha_{1 i j}^{r}$, $\alpha_{2 i j}^{r}$ and $\alpha_{3 i j}^{r}$ represent the slopes in each segment. The three segment hazard functions can be everywhere increasing or decreasing, or bathtub or inverted bathtub shaped. If $\alpha_{3 i j}^{r}<$ 0 then the associated duration distribution is defective with a non-zero probability of no transition from state $i$ to state $j$ at transition $r$. 